www.nature.com/jhg

\title{
Allele frequencies of the $A B C C 11$ gene for earwax phenotypes among ancient populations of Hokkaido, Japan
}

\author{
Takehiro Sato ${ }^{1}$, Tetsuya Amano ${ }^{2}$, Hiroko Ono ${ }^{2}$, Hajime Ishida ${ }^{3}$, Haruto Kodera ${ }^{4}$, Hirofumi Matsumura ${ }^{5}$, \\ Minoru Yoneda ${ }^{6}$ and Ryuichi Masuda ${ }^{1}$
}

Human earwax is classified into wet and dry types, which are determined by a single-nucleotide polymorphism in the adenosine triphosphate-binding cassette, sub-family $\mathrm{C} 11$ ( $A B C C 11)$ gene locus. To investigate the allele frequencies of the $A B C C 11$ locus within ancient populations on the Northern Japanese island of Hokkaido, amplified product-length polymorphisms were analyzed for 50 specimens of the Okhotsk people and 35 specimens of the Jomon and Epi-Jomon people excavated from various archaeological sites of Hokkaido. Of these specimens, 31 Okhotsk and 19 Jomon/Epi-Jomon samples were genotyped successfully. Frequencies of the wet-type allele in the Jomon/Epi-Jomon people, considered a major ancestor of the Ainu, were higher than those of other Northeastern Asian populations, including the modern Ainu. By contrast, in the Okhotsk people, believed to originate from East Siberia, frequencies of the dry-type allele were relatively higher than those in the Ainu and Jomon/Epi-Jomon people. These results suggest that gene flow from the Northeastern Asian Continent to descendants of the Jomon/Epi-Jomon people of Hokkaido through the Okhotsk people occurred, resulting in the establishment of the Ainu. Journal of Human Genetics (2009) 54, 409-413; doi:10.1038/jhg.2009.56; published online 26 June 2009

Keywords: ABCC11; ancient DNA; earwax; Jomon people; Okhotsk people

\section{INTRODUCTION}

There are two types of human earwax (cerumen) produced as a secretion of the apocrine glands. ${ }^{1}$ The earwax phenotypes are inherited through two alleles at a single autosomal locus, namely the dominant wet allele and the recessive dry allele. ${ }^{2}$ The frequencies of the dry type are generally high in East-Asian populations $(80-95 \%),{ }^{2-4}$ but are extremely rare $(0-3 \%)$ in European and African populations. Modest frequencies $(30-50 \%)$ of the dry type are observed in populations of Southern Asia, Central Asia and Western Asia. ${ }^{4}$ Thus, the frequencies of the dry-type earwax are generally distributed along an east-west geographic gradient throughout Eurasia. $^{2-5}$

A recent study ${ }^{6}$ showed that a single-nucleotide polymorphism, $(\mathrm{SNP}) 538 \mathrm{G} \rightarrow \mathrm{A}$ (rs17822931), in the adenosine triphosphate (ATP)binding cassette, sub-family $\mathrm{C} 11$ (ABCC11) gene is responsible for the earwax phenotypes: $\mathrm{G}$ for the dominant (wet) allele and $\mathrm{A}$ for the recessive (dry) allele. The $A B C C 11$ gene encodes the multidrug resistance-associated protein 8 that consists of 1382 amino acids and contains 2 ATP-binding domains and 12 trans-membrane domains. ${ }^{7-9}$ As the mutation $(\mathrm{G} \rightarrow \mathrm{A})$ occurred somewhere in Asia during the dispersion of Homo sapiens after the 'Out of Africa' event(s), and because the alleles are currently distributed at various frequencies in Asian and European populations, ${ }^{10}$ frequencies and distribution patterns of the SNP provide useful information for investigating ancestral origins and gene flow among Asian populations. In addition, the discovery of the causative SNP enables us to infer the phenotypes of ancient people from DNA analysis.

Within Ainu populations, an aboriginal ethnic group of Hokkaido, frequencies of the wet type were reported to be exceptionally higher than those of neighboring Asian populations. ${ }^{1,2}$ The Ainu also has unique characteristics, such as hairiness, wavy hair and deep-set eyes, which differ greatly from those of mainland Japanese. As a result, the subject of Ainu origins has received much attention. ${ }^{11}$ The cultures of Hokkaido Island different from Honshu have developed after the Jomon period. The Yayoi culture, brought by incoming people from continental East/Northeastern Asia to the southwestern part of Japan from the third century BC to the third century AD, was not introduced to Hokkaido, but the Epi-Jomon (third century BC to seventh century $\mathrm{AD})$, Satsumon (eighth to fourteenth century $\mathrm{AD}$ ) and Ainu cultures were developed. In addition, the Okhotsk culture was developed around the coastal regions of the Okhotsk Sea during the fifth to the thirteenth centuries. ${ }^{12}$ As some morphological characteristics of

${ }^{1}$ Department of Natural History Sciences, Graduate School of Science, Hokkaido University, Sapporo, Japan; ${ }^{2}$ Hokkaido University Museum, Sapporo, Japan; ${ }^{3}$ Faculty of Medicine, University of the Ryukyus, Nishihara, Japan; ${ }^{4}$ School of Dental Medicine, Tsurumi University, Yokohama, Japan; ${ }^{5}$ Sapporo Medical University, Sapporo, Japan and ${ }^{6}$ Graduate School of Frontier Sciences, The University of Tokyo, Kashiwa, Japan

Correspondence: Dr R Masuda, Department of Natural History Sciences, Graduate School of Science, Hokkaido University, North 10, West 8, Kita-ku, Sapporo, 060-0810, Japan. E-mail: masudary@ees.hokudai.ac.jp

Received 23 February 2009; revised 26 May 2009; accepted 27 May 2009; published online 26 June 2009 


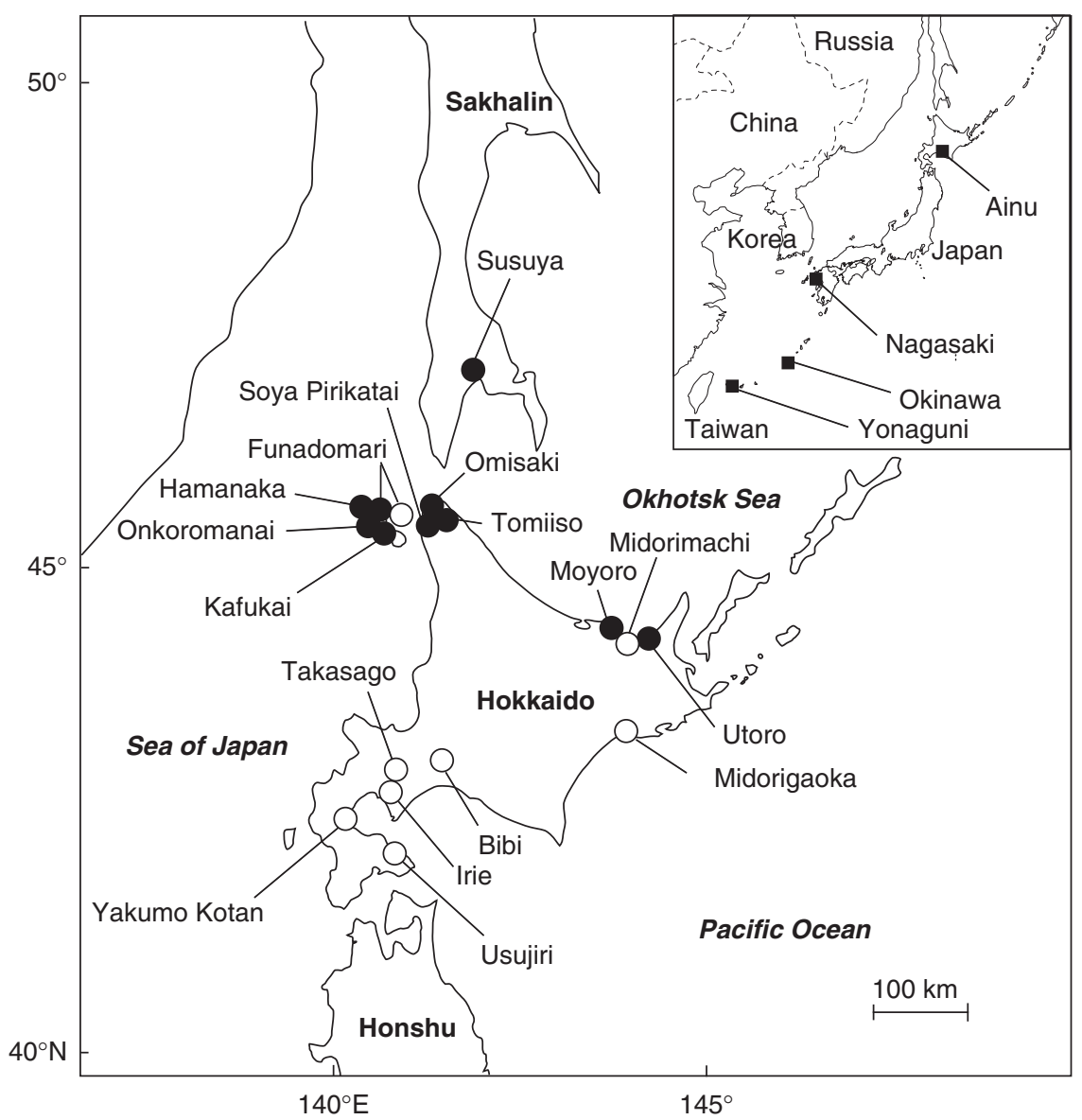

Figure 1 Geographical locations of archaeological sites of the Jomon/Epi-Jomon culture (open circles) and Okhotsk culture (closed circles) from where specimens analyzed in this study were excavated. Closed squares indicate locations of modern Japanese populations in Figure 2.

the Ainu are similar to those of the Neolithic Jomon people of Hokkaido, physical anthropologists have hypothesized that the Ainu are their direct descendants. ${ }^{13,14}$ This scenario has also been supported by the distribution of $\mathrm{Y}$ chromosome haplogroups among modern populations, in which the major haplogroup in the Ainu was observed only in the Japanese archipelago. ${ }^{15}$ On the basis of mtDNA data, multiple origins of the Ainu were suggested with a possible gene flow of haplogroup Y1 from the Nivkhi people in Sakhalin to the Ainu. ${ }^{15}$ Ancient DNA analyses showed that distributions of mtDNA haplogroups are considerably different between the Jomon people and the Ainu. ${ }^{16}$

In addition, an ancient mitochondrial DNA analysis ${ }^{17}$ suggested that the Okhotsk people, who lived throughout the southern coastal regions of the Sea of Okhotsk, including Hokkaido, Sakhalin and the Kuril archipelago from the fifth to the twelfth century AD, were intermediaries in the gene flow from Southeastern Siberia to the Ainu. Morphological studies indicated that the Okhotsk people could have originated in East Siberia, especially around Sakhalin and the lower regions of the Amur River. ${ }^{18-21}$

So far, studies of ancient DNA samples have exclusively depended on mtDNA analysis and have rarely used biparentally inherited autosomal regions. In this study investigating earwax phenotypes from the Jomon, Epi-Jomon and the Okhotsk people, we examined the SNP of the $A B C C 11$ gene using a multiplex-amplified productlength polymorphism (APLP) analysis of ancient DNA. On the basis of comparisons between allele frequencies in ancient populations with those of the Ainu and other modern Asian populations, we discuss the temporal process of high frequencies of the wet earwax type in the Ainu population.

\section{MATERIALS AND METHODS}

\section{Sample collection}

To determine genotypes of the $A B C C 11$ locus in the ancient populations of Hokkaido, 50 skeletal remains of the Okhotsk people and 35 remains of the Jomon and Epi-Jomon people, excavated from 18 archaeological sites (Figure 1) in Hokkaido and Sakhalin, were analyzed. These skeletal remains are housed at the Hokkaido University Museum and the Sapporo Medical University. To avoid a duplicate analysis of skeletal remains from single individuals, parts in the same positions of bones or bones from different graves within one archaeological site were used.

\section{DNA extraction}

DNA was extracted from femurs, ribs, coxal bones, skulls, sacrums or teeth of ancient skeletal remains that were excavated from archeological sites. To avoid surface contamination of external DNA, each bone or tooth was soaked in sodium hypochlorite solution (Nacalai Tesque, Kyoto, Japan) for 5 min, rinsed with DNase-/RNase-free distilled water and allowed to air-dry. Samples were then powdered utilizing a standard dental drill. DNA extraction and concentration were conducted for the subsequent PCR according to the following methods: ${ }^{17,22}$ Approximately $0.2-0.5 \mathrm{~g}$ of bone powder per specimen was decalcified with $30 \mathrm{ml}$ of $0.5 \mathrm{M}$ EDTA (ethylenediaminetetraacetic acid) contain- 


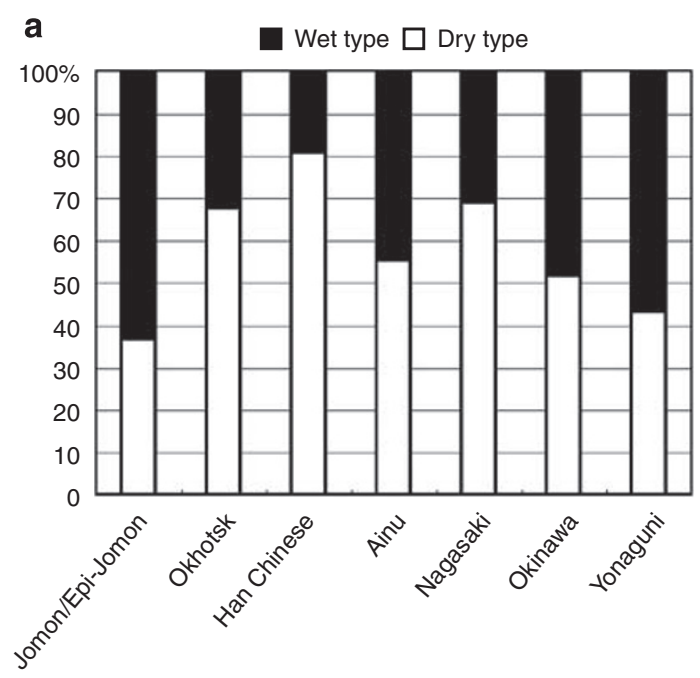

b b $\square$ Allele G $\square$ Allele A

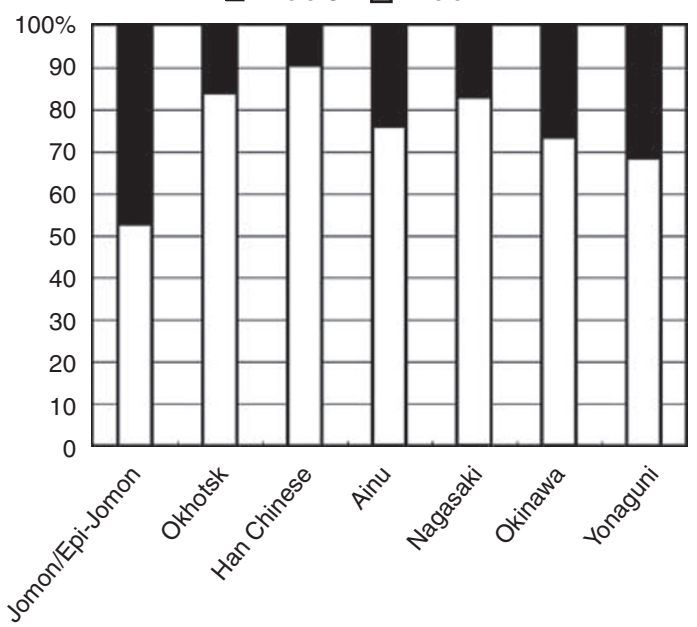

Figure 2 Frequencies of earwax phenotypes (a) and $A B C C 11$ alleles (b) among East-Asian populations. Data of Han Chinese (China), Ainu (Hokkaido, Japan), Nagasaki (Kyushu, Japan), Okinawa (Japan) and Yonaguni (Japan) were cited from Yoshiura et al. (2006).

ing $100 \mu \mathrm{l}$ of proteinase $\mathrm{K}$ concentrated at $10 \mathrm{mg} \mathrm{ml}^{-1}$ and maintained overnight at $37^{\circ} \mathrm{C}$ with rotation. The solution was extracted using the phenol-chloroform extraction method (phenol-chloroform-isoamyl alcohol, 25:24:1). ${ }^{23}$ The extracts were concentrated into $\sim 100 \mathrm{ml}$ of the TE buffer using VivaSpin 6 Concentrators (Sartorius Stedim Biotech, Goettingen, Germany) and submitted to PCR.

\section{Multiplex APLP analysis}

To analyze the SNP (rs17822931) and the 27-bp deletion in the ABCC11 gene of ancient Hokkaido specimens, the multiplex APLP method ${ }^{10}$ was used. The 27-bp deletion in $A B C C 11$ exon 29 leads to a loss of function of the protein and acts as a dry allele. ${ }^{6}$ An aliquot $(1 \mu \mathrm{l})$ of the DNA extract was used as a template for multiplex PCR. PCR amplification was carried out in $20 \mu$ of reaction mixtures containing reagents of the Multiplex PCR Kit (Qiagen, Hilden, Germany), optimum concentrations of each primer ${ }^{10}$ and $0.4 \mu \mathrm{g} \mu \mathrm{l}^{-1}$ of bovine serum albumin (20 $\mathrm{mg} \mathrm{ml}^{-1}$, Roche, Basel, Switzerland). The PCR conditions were $95^{\circ} \mathrm{C}$ for 15 mins, followed by 35 cycles of $94^{\circ} \mathrm{C}$ for $30 \mathrm{~s}, 60^{\circ} \mathrm{C}$ for 3 mins, $72^{\circ} \mathrm{C}$ for $90 \mathrm{~s}$, and $1 \mathrm{cycle}$ of $72{ }^{\circ} \mathrm{C}$ for 10 mins.

An aliquot $(10 \mu \mathrm{l})$ of the PCR product was separated by electrophoresis in a $13-\mathrm{cm}$ native polyacrylamide gel $(10 \% \mathrm{~T}, 5 \% \mathrm{C}, \mathrm{T}=$ [acrylamide + methylenebisacrylamide]/[acrylamide + methylenebisarcylamide + water ], $\mathrm{C}=$ [methylenebisacrylamide]/[acrylamide + methylenebisacrylamide $]$ ) containing $375 \mathrm{~mm}$ Tris- $\mathrm{NaOH}$ buffer $(\mathrm{pH}$ 8.9) with the running buffer (12.5 mm Tris, $96 \mathrm{~mm}$ glycine; $\mathrm{pH} 8.3$ ). The DNA bands were detected using an ultraviolet (UV) illuminator after staining with ethidium bromide.

\section{Contamination precautions}

The following standard contamination precautions were taken: separation of pre- and post-PCR experimental areas, use of gloves, face masks and laboratory coats, usage of disposable filter-plugged pipette tips and disposable tubes, treatment with DNA-AWAY (Molecular BioProducts, San Diego, CA, USA), UV irradiation of equipments and bench, negative extraction controls and negative PCR controls.

\section{Data analysis}

Genotypic data of the ancient populations of Hokkaido were compared with previously reported data from modern East-Asian populations (Figure 2). Data from one Epi-Jomon specimen (an individual analyzed successfully) were included in those of the Jomon people, and named 'Jomon/Epi-Jomon' below. Allele frequencies of the $A B C C 11$ locus were cited from five populations, namely 193 Northern Han Chinese, 58 Ainu, 126 people of Nagasaki, 58 people of Okinawa and 30 people of the Yonaguni Island. ${ }^{6}$ The exact test of population differentiation was carried out with Arlequin 3.11.24

\section{RESULTS AND DISCUSSION}

In this study, the DNA fragment, including the SNP, 538G $\rightarrow$ A (rs17822931), in the ABCC11 gene, was successfully PCR-amplified and genotyped from 31 of 50 Okhotsk specimens and from 19 of 35 Jomon/Epi-Jomon specimens (Table 1). No successful results were obtained from the remaining samples because of possible DNA degradation. In addition, fragments, including the 27-bp deletion region in ABCC11 exon 29, were PCR-amplified from 30 of the 31 Okhotsk specimens and from 14 of the 19 Jomon/Epi-Jomon specimens that were genotyped for the SNP. The deletion $\Delta 27$ located in allele $G$ leads this allele to lose function resulting in the dry phenotype. ${ }^{6}$ In this study, however, $\Delta 27$ was not detected from any specimens (Table 1).

The frequency of allele A of the Jomon/Epi-Jomon people (0.526) was lower than that of the modern people of Northeastern Asia (0.683-0.904) (Figure 2). This suggests that effects of gene flow from ancestors of northeast Asians to the Jomon/Epi-Jomon people were not stronger than those to other East-Asian populations, including Northern Han Chinese and modern Japanese. Furthermore, the relatively lower frequency (0.759) of allele A of the Ainu was likely derived from low frequencies of allele $\mathrm{A}$ in the Jomon/Epi-Jomon people.

On the other hand, the frequency of allele A of the Okhotsk people (0.839) was higher than those of the Ainu and Jomon/Epi-Jomon people. This indicates that the Okhotsk people were influenced by northeastern continental populations. In fact, morphological ${ }^{18-21,25}$ and mitochondrial $\mathrm{DNA}^{17}$ analyses showed that the Okhotsk people were much more closely related to people currently living around Sakhalin and in the lower regions of the Amur River. The exact test showed that the differentiation between the Jomon/Epi-Jomon people and the Okhotsk people was statistically significant $(P=0.0005)$. This suggests that these populations are genetically different from each other. The frequency of allele A in the Ainu (0.759) was higher than that in Jomon/Epi-Jomon people (0.526) (Figure 2). It shows that gene flow from Northeastern Asian populations to the Ainu was stronger than that from Northeastern Asian populations to the 
Table 1 The $A B C C 11$ genotypes of the Jomon/Epi-Jomon and Okhotsk specimens

\begin{tabular}{|c|c|c|c|}
\hline \multirow[b]{2}{*}{ Specimen no. } & \multirow[b]{2}{*}{ Archaeological site } & \multicolumn{2}{|c|}{ Genotype } \\
\hline & & rs17822931 & $D 27^{a}$ \\
\hline \multicolumn{4}{|c|}{ Jomon/Epi-Jomon people } \\
\hline $\mathrm{JM}-1$ & Midorimachi & $A A$ & ND \\
\hline $\mathrm{JM}-2$ & Bibi & GA & - \\
\hline $\mathrm{JM}-3$ & Yakumo Kotan & $A A$ & - \\
\hline $\mathrm{JM}-4$ & Yakumo Kotan & $A A$ & - \\
\hline$J M-5$ & Yakumo Kotan & $A A$ & - \\
\hline JM-6 & Irie & GG & - \\
\hline $\mathrm{JM}-7$ & Funadomari & GG & - \\
\hline$J M-8$ & Funadomari & GA & - \\
\hline JM-9 & Funadomari & GA & - \\
\hline JM-10 & Funadomari & GG & - \\
\hline$J M-11$ & Funadomari & $\mathrm{GA}$ & - \\
\hline $\mathrm{JM}-12$ & Funadomari & GG & ND \\
\hline $\mathrm{JM}-13$ & Midorigaoka & $A A$ & ND \\
\hline$J M-14$ & Midorigaoka & $A A$ & ND \\
\hline$J M-15$ & Midorigaoka & GG & ND \\
\hline $\mathrm{JM}-16$ & Usujiri & $A A$ & - \\
\hline $\mathrm{JM}-17$ & Takasago & $\mathrm{GA}$ & - \\
\hline$J M-18$ & Funadomari & GG & - \\
\hline EPJ-1 & Onkoromanai & GA & - \\
\hline \multicolumn{4}{|l|}{ Okhotsk people } \\
\hline $\mathrm{OKH}-1$ & Moyoro & $A A$ & - \\
\hline $\mathrm{OKH}-2$ & Moyoro & $A A$ & - \\
\hline OKH-3 & Moyoro & $A A$ & - \\
\hline $\mathrm{OKH}-4$ & Moyoro & $A A$ & - \\
\hline $\mathrm{OKH}-5$ & Moyoro & $A A$ & - \\
\hline OKH-6 & Utoro & $A A$ & - \\
\hline OKH-7 & Utoro & $A A$ & - \\
\hline OKH-8 & Utoro & $A A$ & - \\
\hline OKH-9 & Omisaki & $A A$ & - \\
\hline OKH-10 & Omisaki & GA & - \\
\hline OKH-11 & Omisaki & $\mathrm{GA}$ & - \\
\hline OKH-12 & Omisaki & GA & - \\
\hline OKH-13 & Omisaki & $A A$ & - \\
\hline OKH-14 & Omisaki & $A A$ & - \\
\hline OKH-15 & Omisaki & $A A$ & - \\
\hline OKH-16 & Hamanaka & $A A$ & - \\
\hline OKH-17 & Hamanaka & $A A$ & - \\
\hline OKH-18 & Hamanaka & $\mathrm{GA}$ & - \\
\hline OKH-19 & Hamanaka & $A A$ & - \\
\hline OKH-20 & Hamanaka & $A A$ & ND \\
\hline OKH-21 & Hamanaka & $\mathrm{GA}$ & - \\
\hline OKH-22 & Hamanaka & $\mathrm{GA}$ & - \\
\hline OKH-23 & Hamanaka & $A A$ & - \\
\hline OKH-24 & Hamanaka & $\mathrm{GA}$ & - \\
\hline OKH-25 & Hamanaka & $\mathrm{GA}$ & - \\
\hline OKH-26 & Susuya & $A A$ & - \\
\hline OKH-27 & Susuya & $A A$ & - \\
\hline OKH-28 & Pirikatai & $\mathrm{GA}$ & - \\
\hline OKH-29 & Tomoiso & $\mathrm{GA}$ & - \\
\hline OKH-30 & Funadomari & $A A$ & - \\
\hline OKH-31 & Funadomari & $A A$ & - \\
\hline
\end{tabular}

Jomon/Epi-Jomon people. If ancestors of the Ainu were only descendants of the Jomon people, the frequency of allele A of the Ainu may be similar to that of the Jomon/Epi-Jomon people. However, the frequency of allele A of the Ainu (0.759) was higher than that of the Jomon/Epi-Jomon people (0.526) and lower than that of the Okhotsk people (0.839). These results suggest that the median value of the allele A frequency in the Ainu was established by the gene flow from people with a high frequency of allele A (probably the Okhotsk people) to descendants of the Jomon/Epi-Jomon people. It means that the Okhotsk people joined the descendants of the Jomon/Epi-Jomon people, resulting in Ainu with a moderate frequency of allele A. Mitochondrial DNA analyses ${ }^{15,17}$ reported the occurrence of mtDNA haplogroups common to both Okhotsk and Ainu, suggesting a genetic contribution by the Okhotsk people to Ainu populations. In addition, the morphological study ${ }^{26}$ reported some morphological association of the Ainu with northeastern continental populations. These findings strongly support gene flow from the Okhotsk to the Jomon lineage, resulting in the establishment of the Ainu. However, modern Ainu has also mixed in the past with mainland Japanese, especially since the beginning of the Meiji era when colonists moved into Hokkaido from Honshu. As the frequency data of the Ainu ${ }^{6}$ used for comparison in this study were obtained from very modern Ainu, it may be difficult at this stage to assess the extent to which mainland Japanese contributed to the higher frequencies of allele A in modern Ainu relative to people of the Jomon/Epi-Jomon cultures. In addition, these Ainu data were obtained from the Biratori-Nibutani village ${ }^{6}$ and not from coastal regions of the Okhotsk Sea. Future analysis of the allele frequency from earlier stages of the Ainu culture from the coastal regions of the Okhotsk Sea could clarify the extent of gene flow from the Okhotsk people to the Ainu.

This study of the SNP of the ABCC11 gene showed genetic structures of ancient populations in Hokkaido. The SNP would be a useful genetic marker for inferring histories of human populations.

\section{ACKNOWLEDGEMENTS}

We thank Dr. Ryosuke Kimura (University of the Ryukyus) and James Taylor (University of Washington) for their helpful comments on this manuscript.

This study was supported in part by Grants-in-Aid for Scientific Research (Nos. 19657028, 18370099, 20-1887) from the Japan Society for the Promotion of Science (JSPS) and the grant from the Suhara Memorial Foundation. The first author (TS) is a JSPS Fellow.

1 Adachi, B. Das Ohrenschmalz als Rassenmerkmal und der Rassengeruch ('Achselgeruch') nebst dem Rassenunterschied der Schweissdrüsen. Z. Rassenk 6, 273-307 (1937).

2 Matsunaga, E. The dimorphism in human normal cerumen. Ann. Hum. Genet. 25, 273-286 (1962).

3 Omoto, K. Polymorphic traits in peoples of eastern Asia and the Pacific. Isr. J. Med. Sci. 9, 1195-1215 (1973).

4 Petrakis, N. L., Pingke, U., Petrakis, S. J. \& Petrakis, S. L. Evidence for a genetic cline in earwax type in the Middle East and Southeast Asia. Am. J. Phys. Anthropol. 35, 141-144 (1971).

5 Petrakis, N. L., Molohon, K. T. \& Tepper, D. J. Cerumen in American Indians: genetic implications of sticky and dry types. Science 158, 1992-1993 (1967).

6 Yoshiura, K., Kinoshita, A., Ishida, T., Ninokata, A., Ishikawa, T., Kaname, T. et al. A SNP in the ABCC11 gene is the determinant of human earwax type. Nat. Genet. 38, 324-330 (2006).

7 Yabuuchi, H., Shimizu, H., Takayanagi, S. \& Ishikawa, T. Multiple splicing variants of two new human ATP-binding cassette transporters, ABCC11 and ABCC12. Biochem. Biophys. Res. Commun. 288, 933-939 (2001).

8 Tammur, J., Prades, C., Arnold, I., Rzhetsky, A., Hutchinson, A., Adachi, M. et al. Two new genes from the human ATP-binding cassette transporter superfamily, ABCC11 and ABCC12, tandemly duplicated on chromosome 16q12. Gene 273, 89-96 (2001). 
9 Bera, T. K., Lee, S., Salvatore, G., Lee, B. \& Pastan, I. MRP8, a new member of ABC transporter superfamily, identified by EST database mining and gene prediction program, is highly expressed in breast cancer. Mol. Med. 7, 509-516 (2001).

10 Kitano, T., Yuasa, I., Yamazaki, K., Nakayashiki, N., Miyoshi, A., Park, K. S. et al. Allele frequencies of a SNP and a 27-bp deletion that are the determinant of earwax type in the ABCC11 gene. Leg. Med. (Tokyo) 10, 113-114 (2008).

11 Hanihara, K. Ainu and Ryukyus (Okinawa Islanders). in Recent Progress of Natura Sciences in Japan Vol. 8 (ed Kondo, S.) 25-30 (Science Council of Japan, Tokyo, 1983).

12 Amano, T. What is the Okhotsk culture? in Epi-Jomon and Okhotsk culture (eds Nomura, T. \& Utagawa, Y.) 110-133 (Hokkaido Shimbun, Sapporo, 2003, in Japanese).

13 Yamaguchi, B. A review of the osteological characteristics of the Jomon population in prehistoric Japan. J. Anthropol. Soc. Nippon. 90, 77-90 (1982).

14 Hanihara, K. Dual structure model for the population history of the Japanese. Jpn Rev. 2, 1-33 (1991).

15 Tajima, A., Hayami, M., Tokunaga, K., Juji, T., Matsuo, M., Marzuki, S et al. Genetic origins of the Ainu inferred from combined DNA analyses of maternal and paternal lineages. J. Hum. Genet. 49, 187-193 (2004).

16 Adachi, N., Shinoda, K., Umetsu, K. \& Matsumura, H. Mitochondrial DNA analysis of Jomon skeletons from the Funadomari site, Hokkaido, and its implication for the origins of Native American. Am. J. Phys. Anthropol. 138, 255-265 (2009).
17 Sato, T., Amano, T., Ono, H., Ishida, H., Kodera, H., Matsumura, H. et al. Origins and genetic features of the Okhotsk people, revealed by ancient mitochondrial DNA analysis. J. Hum. Genet. 52, 618-627 (2007).

18 Ishida, H. Morphological studies of Okhotsk crania from Omisaki, Hokkaido. J. Anthropol. Soc. Nippon 96, 17-45 (1988)

19 Ishida, H. Metric and nonmetric cranial variation of the prehistoric Okhotsk people. Anthropol. Sci. 104, 233-258 (1996).

20 Kozintsev, A. G. Ainu, Japanese, their ancestors and neighbors: cranioscopic data. J. Anthropol. Soc. Nippon 98, 247-267 (1990)

21 Kozintsev, A. G. Prehistoric and recent populations of Japan: multivariate analysis of cranioscopic data. Arctic Anthropol. 29, 104-111 (1992).

22 Masuda, R., Amano, T. \& Ono, H. Ancient DNA analysis of brown bear (Ursus arctos) remains from the archaeological site of Rebun Island, Hokkaido, Japan. Zool. Sci. 18, 741-751 (2001).

23 Sambrook, J., Fritsch, E. F. \& Maniatis, T. Molecular Cloning: A Laboratory Manual 2nd edn (Cold Spring Harbor Laboratory Press, New York, 1989).

24 Komesu, A., Hanihara, T., Amano, T., Ono, H., Yoneda, M., Dodo, Y. et al. Nonmetric cranial variation in human skeleton remains associated with Okhotsk culture. Antholopol. Sci. 116, 33-47 (2008).

25 Excoffier, L., Laval, G. \& Schneider, S. Arlequin ver. 3.0: An integrated software package for population genetics data analysis. Bioinfomatics Online 1, 47-50 (2005).

26 Hanihara, T., Yoshida, K. \& Ishida, H. Craniometric variation of the Ainu: an assessment of differential gene flow from northeast Asia into northern Japan, Hokkaido. Am. J. Phys. Anthropol. 137, 283-293 (2008). 